\title{
Daisy, Oswald e o Processo Erosivo do Modernismo Brasileiro
}

\author{
[ Daisy, Oswald and the erosive process of Brazilian Modernism
}

\section{Leandro Pasini ${ }^{\mathrm{x}}$}

RESUMO O objetivo deste ensaio é analisar e interpretar a figura de Maria de Lourdes Castro Pontes, a Daisy ou Miss Cyclone do diário coletivo O perfeito cozinheiro das almas deste mundo (I9I8), no pano de fundo da história do Modernismo brasileiro. Nesse sentido, essa autora-personagem torna-se portadora de especificidades subjetiva e estética que podem abrir novas perspectivas para a abordagem do Modernismo, bem como da obra e da figura de Oswald de Andrade. A hipótese que proponho é a de que a imagem incompleta e fragmentária que temos de Daisy equivale à da própria noção que temos do Modernismo brasileiro. - Palavras-chave Daisy; Oswald de Andrade; O perfeito cozinheiro das almas deste mundo; Modernismo brasileiro; Questões de gênero. - ABSTRACT The purpose of this article is to analyse and interpret the figure of Maria Lourdes Castro, called Daisy or Miss Cyclone in the collective diary $O$ perfeito cozinheiro das almas deste mundo (I9I8) in the background of the history of Brazilian Modernism. In this sense, this author-character has subjective and aesthetical specificities which can open new perspectives for the aproach of Brazilian Modernism, as well as the literary works and the personality of Oswald de Andrade. My hypothesis is that her incomplete and fragmentary image points to a more drastic incompleteness and fragmentation: that of the very notion we have of Brazilian Modernism. - KEYwORDS ODaisy; Oswald de Andrade; O perfeito cozinheiro das almas deste mundo; Brazilian Modernism; Gender Issues.

Recebido em 02 de fevereiro de 2015

Aprovado em 29 de abril de 2015

Pasini, Leandro. Daisy, Oswald e o Processo Erosivo do Modernismo Brasileiro. Revista do Instituto de Estudos Brasileiros, Brasil, n. 6I, p. I40-I58, ago. 2015.

DoI: http://dx.doi.org/IO.II606/issn.23I6-90IX.voi6IpI40-I58

I Universidade Federal de São Paulo (Unifesp, São Paulo, Brasil) 
les secrets bien plus beaux

de n'avoir pas été dits

les mots pas écrits

les pas effacés

les cendres envolées sans nom

sans plaque de marbre

violant le souvenir

O perfeito cozinheiro das almas deste mundo - diário de um grupo de amigos que se reunia na garçonnière de Oswald de Andrade, situada na rua Libero Badaró, 67, $3^{\circ}$ andar, sala 2 -, escrito ao longo do ano de I9I8, só foi publicado em I987, embora boa parte dele tenha sido reproduzida nas memórias de Oswald, publicadas em I954, sob o título Um homem sem profissão. O que a cronologia dessas edições aponta é o interesse descontínuo, contado a espaços de décadas, que o diário despertou. A questão da divulgação de $O$ perfeito cozinheiro... torna-se ainda mais surpreendente se pensarmos nos autores que o compõem e em sua posição temporal diante dos eventos que se lhe seguiram, como sobretudo a composição do grupo modernista em São Paulo em torno de I920 e a presença de alguns de seus integrantes na realização da Semana de Arte Moderna em I922. Na reconstrução retrospectiva dos fatos artístico-literários que antecedem à Semana, o grupo que frequentava a garçonnière de Oswald e que escreveu nas páginas do diário estaria situado entre a exposição de Anita Malfatti em I9I7 e o aparecimento da obra Brecheret em I920. No entanto, Mário da Silva Brito, em sua bem documentada história dos “antecedentes" da Semana, não se refere a $O$ perfeito cozinheiro..., pulando diretamente do ano de I9I7 para I920². Entre os frequentadores da garçonnière e autores do diário, alguns passaram a integrar a

I Consultado em edição fac-similar (I987) e na edição em transcrição tipográfica de Jorge Schwartz (I992, republicada em 20I4). A numeração das páginas do diário é a mesma em todas as edições.

2 BRITO, Mário da Silva. História do modernismo brasileiro. Rio de Janeiro, Civilização Brasileira, I997 (I ${ }^{a}$. Edição de I958). Lembrando ainda que Mário da Silva Brito fez um relato sobre o diário em seu texto “As Metamorfoses de Oswald de Andrade”, incluído em Ângulo e horizonte. São Paulo, Livraria Martins, I969, p. 5-Io, posteriormente publicado na introdução da edição fac-similar de O perfeito cozinheiro das almas deste mundo (I987) e reproduzido em suas demais edições. 
história da literatura brasileira, como Oswald de Andrade, Monteiro Lobato, Menotti del Picchia e Guilherme de Almeida, outros foram viver suas vidas sem literatura, como Pedro Rodrigues de Almeida, Edmundo Amaral, Léo Vaz, Sarti Prado, Vicente Rao e Ignácio Ferreira da Costa³. Só uma de suas personagens teve a vida circunscrita e consumida, literária e extraliterariamente, nas páginas de $O$ perfeito cozinheiro...: a única mulher do grupo, Maria de Lourdes Castro Pontes, que morreu precocemente aos I9 anos em I9I9, data em que finda o diário.

Chamada alternadamente de Deisi, Daisy, Dasinha, Miss Tufão e Miss Cyclone ${ }^{4}$ no diário, ela só foi apresentada à história literária brasileira nas memórias de Oswald (datadas de I954), quando este relata que a professora de piano de sua companheira Kamiá "traz para o almoço uma prima esquelética e dramática, com uma mecha de cabelos na testa. Chamavam-na Deisi. Parece inteligente. Convido-a cinicamente a amar-me. Ela responde: - Sim, mas sem premeditação. Quando nos encontrarmos um dia. Pergunto-lhe o que acha dos homens. — Uns canalhas! — E as mulheres? Também!"’. É possível deduzir ao menos duas implicações desse primeiro diálogo. Em primeiro lugar, a união indissolúvel de sua vida à de Oswald, não somente porque ela ganha vida literária por meio dele - assunto a que retornarei - mas principalmente porque Oswald é um interlocutor receptivo, na São Paulo dos anos I9Io, ao tipo de sarcasmo inventivo com que Daisy conduz o diálogo. Em segundo, a primeira aparição de Daisy na constituição história do Modernismo já demonstra algo de sua ambivalência entre pessimismo melancólico e agilidade irônica moderna, o que a coloca no mesmo paradigma de transição subjetiva e estética em que se encontram os escritores-personagens de $O$ perfeito cozinheiro..., com as diferenças social e de gênero que darão complexidade à sua convivência com o círculo intelectual de Oswald. O desfecho desse relacionamento segue o seguinte roteiro: a presença de Daisy na garçonnière, a sua transformação em "batuta invisível" dos autores-personagens do diário, os problemas familiares e de saúde, a consolidação de sua relação amorosa com Oswald, as desconfianças deste, um aborto malsucedido, o seu casamento in extremis e a sua morte alguns dias depois.

O objetivo deste ensaio é analisar e interpretar a figura de Daisy no pano de fundo da história do Modernismo brasileiro, vendo nela uma personagem portadora de especificidades subjetiva e estética que podem abrir novas perspectivas para a abordagem do Modernismo, bem como da obra e da figura de Oswald de Andrade. Para isso, pretende-se fazer uma leitura de $O$ perfeito cozinheiro... e, por meio do diário, traçar o perfil literário de Daisy pela análise de seus escritos e de sua posição no grupo. A hipótese que proponho é a de que a imagem incompleta e fragmentária que temos de Daisy equivale à da própria noção que temos do Modernismo

3 Os personagens e alguns dos pseudônimos são apresentados por Oswald em suas memórias: ANDRADE, Oswald de. Um homem sem profissão I: sob as ordens de mamãe. São Paulo, Globo, 2002, p. I6I. Para maior informação sobre eles, consultar BOAVENTURA, Maria Eugênia. O salão e a selva: uma biografia ilustrada de Oswald de Andrade. Campinas-SP/ São Paulo, Edunicamp/ Editora Ex Libris, I995, p. 45-47.

4 Opto por Daisy, grafia dominante de Oswald em suas memórias.

5 ANDRADE, Oswald de. Um homem sem profissão..., op. cit., p. I59. Esse diálogo foi reproduzido por Oswald no início do romance A estrela de absinto (I927). 
brasileiro. Em relação ao Modernismo, Cecília de Lara nota que "para cada figura que sobressaiu, muitas outras ficaram nos bastidores, mas tiveram papel decisivo no debate de ideias, na abertura de caminhos". Desse modo, o caráter incompleto, problemático e cheio de zonas de sombra dos escritos de Daisy se projetam na história do Modernismo brasileiro e o revelam como um movimento de fronteiras móveis e ainda não suficientemente exploradas pela crítica. Portanto, este artigo se coloca ao mesmo tempo como uma crítica de gênero no âmbito do Modernismo e uma proposta de historiografia revisionista do movimento. Essa historiografia, cujo âmbito aqui apenas se esboça, incluiria personagens e obras tidas por secundárias, esquecidas e/ou abandonadas, bem como grupos na mesma posição; além disso, recuperaria o caráter coletivo de sua produção como pressuposto dialético da originalidade individual de seus principais autores. Nesse viés, notaria igualmente o seu aspecto erosivo, de constantes desarticulações e rearticulações, que teria a perda como elemento constitutivo e cuja tendência dispersiva demandava racionalizações constantes do seu significado e do seu sentido.

Antes, contudo, é preciso pensar na fenomenologia histórica de $O$ perfeito cozinheiro... em sua temporalidade ambivalente em relação ao Modernismo brasileiro. O seu aparecimento é posterior ao ciclo histórico tradicional do Modernismo (I922-I945) e depende da consolidação da obra de Oswald. O diário é, portanto, tributário do projeto de publicação de suas "obras completas". Se pensarmos, então, na lógica da temporalidade modernista, $O$ perfeito cozinheiro das almas deste mundo está depois (trechos em I954, integral em I987) e não antes do movimento (I9I8). A transformação do diário em livro é um resultado do ciclo, constituído como tal a partir da consolidação do Modernismo no plano da crítica universitária e da historiografia literária brasileira, ${ }^{7}$ e somente a partir daí é possível remontar os seus "antes" e "antecedentes", construídos a posteriori. Contudo, estabelecido esse "antes", é possível inquirir problemas, localizá-los e referi-los ao que o movimento veio a ser, com suas promessas, suas realizações e seus fracassos. Haroldo de Campos fala, em relação ao diário, de seu "sentido prospectivo, já agora apostilado à história (à História do Modernismo Brasileiro)"'. O paradoxo que se abre nesse apostilamento é o de que, devido à consolidação da história do Modernismo e de seus protagonistas, novos

6 LARA, Cecília de. Introdução. In: Pressão afetiva e aquecimento intelectual: cartas de Antônio de Alcântara Machado a Prudente de Moraes, neto. São Paulo, Giordano/ Lemos/ Educ, I997, p. I4.

7 É quimérico propor uma data taxativa para o fim do ciclo modernista no Brasil. As hipóteses mais reiteradas o datam em I930, como a de Mário da Silva Brito: “Tinha o Modernismo, pelas alturas de [I9]30, cumprido o seu ciclo histórico”. A Revolução Modernista. In: COUTINHO, Afrânio (org.). A literatura no Brasil. São Paulo, Global, 2004. v. 6. p. 39; ou em I945, como em Antonio Candido. Literatura e Cultura de I900 a I945.In: . Literatura e sociedade. Rio de Janeiro, Ouro sobre Azul, 2008, p. II9. Pensando na poesia modernista, devido às obras de síntese de Carlos Drummond de Andrade (A rosa do povo), de Murilo Mendes (As metamorfoses, I944; Mundo enigma, I945), de Oswald de Andrade (Poesias reunidas de O. de Andrade) e a morte de Mário de Andrade, julgo o ano de 1945 como o mais adequado, sem, contudo, pretender com isso subscrever ortodoxias estanques em termos de cronologia.

8 CAMPOS, Haroldo de. Réquiem para Miss Cyclone, musa dialógica da pré-história textual oswaldiana. In: ANDRADE, Oswald de. O perfeito cozinheiro das almas deste mundo. São Paulo, Globo, I992, p. xxiii. 
roteiros e novos protagonistas vêm à luz: é só a partir do projeto editorial destinado a tornar a obra e a personalidade de Oswald objeto de estudos acadêmicos que Daisy passa a integrar em potência a história literária brasileira'? Pela transformação do Modernismo brasileiro em um discurso lógico, historicizado e institucionalizado, aparecem, agitam e virtualmente modificam a imagem do movimento aqueles personagens, textos e fatos não abarcados pelo projeto de consolidar a obra de seus protagonistas.

Surge da publicação tardia de $O$ perfeito cozinheiro... não apenas uma nova personagem, Daisy, mas o próprio reconhecimento do diário como objeto estético ("obra") que é tardio e depende, por um lado, do que Antonio Candido chamou de "normalização", "generalização" do Modernismo, ${ }^{\text {Io }} \mathrm{e}$, por outro, de um novo impulso experimental por parte dos poetas concretistas. Por uma feliz convergência, a dinâmica lúdica, estruturada no imprevisto, na provocação, nos jogos com a ideia do literário e na sobreposição de escritos, desenhos, colagens etc. vai parecer décadas depois uma realização de alguns dos impulsos mais radicais da vanguarda internacional, como as colagens dadaístas e surrealistas. No entanto, o estatuto do diário no momento em que ele era construído não correspondia, para nenhum de seus autores-personagens, a uma ideia de obra nem de arte. Teresa Virgínia de Almeida, ao estudar a distância temporal que diferencia o modo de conceber o diário, escreve:

Ao se perguntar qual a função social daquele diário coletivo à época de sua produção, a resposta pode ser bastante simples: um despretensioso meio de comunicação entre amigos no reduzido contexto de uma garçonnière. Pelo menos em tese, não há na produção daquele volume qualquer inscrição de um leitor potencial que não pertença ao grupo de produtores. E creio que o fato de o diário ter figurado durante seis décadas apenas como um entre vários documentos sob a guarda de um dos filhos de Oswald de Andrade faz suspeitar que nem o mesmo poeta atribuía valor estético ao volume. O valor do diário, até então, era o de documentar um período da biografia de Oswald, sua relação com os amigos e com Daisy. ${ }^{\text {II }}$

Em uma dialética própria, é o esforço de codificação do Modernismo que abre a possibilidade de novas codificações do movimento, afastando assim a ideia de que consolidar uma tradição literária modernista seja sinônimo de um fechamento do

9 Além de seus escritos em O perfeito cozinheiro das almas deste mundo, Daisy escreveu um diário, que está preservado no Fundo Oswald de Andrade, Cedae, Unicamp, que também guarda a sua correspondência com Oswald de Andrade. Diário e correspondência estão descritos em BOAVENTURA, Maria Eugênia, op. cit., p. 67-70. Como esse diário pessoal ainda não foi publicado, e a sua leitura ainda se ressente da dificuldade apresentada por um manuscrito, por vezes pouco compreensível, o juízo que se pode fazer de seus escritos ainda se limita aqui ao que Daisy escreveu em O perfeito cozinheiro...

Io CANDIDO, Antonio. A Revolução de 30 e a Cultura. In: A educação pela noite. Rio de Janeiro, Ouro sobre Azul, 2006, p. 223.

II ALMEIDA, Tereza Virgínia de. A ausência lilás da Semana de Arte Moderna: o olhar pós-moderno. Florianópolis, Letras Contemporâneas, I998, p. 80. 
discurso em torno de uns poucos autores e obras. Voltando ao período em que o diário foi composto, é interessante notar que, dois anos depois, Oswald estará presente no grupo da revista Papel e Tinta (I920-I92I), que dirige com Menotti del Picchia e na qual escrevem Guilherme de Almeida e Mário de Andrade. Aos olhos atuais, ela dá uma sensação de retrocesso em relação às ousadias de $O$ perfeito cozinheiro... Tratava-se então de um grupo com uma proposta coletiva, pública e com um interesse artístico e literário comum, irmanado por uma vaga ideia de renovação e nacionalização, mas que não recuperava nenhum elemento da experiência anterior do diário. Por um lado, isso reafirma que $O$ perfeito cozinheiro... foi se tornando uma "obra" ao longo do tempo, e não por intenção de seus autores-personagens; por outro, que a história do Modernismo não se constitui por uma acumulação linear e teleológica, mas por um ritmo constante de perdas e rearticulações.

Nesse sentido, o aparecimento tardio da publicação e de Daisy abre uma perspectiva diferente sobre a lógica do movimento modernista. Ele é um índice de uma longa lista de promessas não realizadas no interior do movimento, das ausências, dos abandonos e das baixas que, pelos mais diversos fatores, o acompanharam. Apenas dois exemplos, escolhidos ao acaso: a produção poética de Carlos Drummond de Andrade ao longo da década de I920, que projetara a publicação dos títulos Teia de aranha, Preguiça, Os poemas da triste alegria e Minha terra tem palmeiras, ${ }^{\mathrm{T} 2}$ os quais ainda aguardam maior conhecimento por parte do público para se avaliar melhor o desenvolvimento de sua poética e sua relação com o Modernismo; e o ineditismo do pernambucano Benedito Monteiro, do alagoano Aloísio Branco e do prometido livro que lançaria a Antropofagia no Espírito Santo, Sabedoria do mal, de Garcia de Rezende. Se pensarmos ainda na consolidação do Modernismo como sistema literário nacional na década de I920, é preciso constatar o que configuraria como terceiro exemplo: que os grupos - entre eles o de Porto Alegre, o de Belém e o de Fortaleza - não estão integrados a uma reflexão sobre o movimento que modificasse decisivamente a sua imagem. Paro por aqui a enumeração que, se fosse continuada, ocuparia talvez todo o espaço do texto. Trata-se apenas da exposição de algumas perdas que o movimento sofreu gradativamente para dar uma ideia vaga do quadro geral e reforçar as dificuldades que a sua continuidade enfrentou, bem como a autoconsciência que precisou adquirir. Assim, podemos perceber que enquanto o movimento mantinha coerência em determinados autores, como Mário, Drummond, Bandeira e Oswald, ele ao mesmo tempo se desmanchava coletivamente e parecia morrer a cada passo, o que revela a instabilidade do Modernismo pensado em sincronia com o seu contexto. Nessa perspectiva, a desaparição prematura de

I2 CURY, Maria Zilda Ferreira. Horizontes modernistas: o jovem Drummond e seu grupo em papel jornal. Belo Horizonte, Autêntica, I998, p. I6I-I62. Em 20I2, foi publicado, de Drummond, o livro Os 25 poemas da triste alegria. São Paulo, Cosac Naify, 20I2. O manuscrito de Minha terra tem palmeiras (I926) está no Instituto de Estudos Brasileiros (USP), e parte de seus poemas estão publicados em Alguma poesia (I930). Quanto a Teia de aranha e Preguiça, constariam, segundo entrevista do poeta reproduzida por Maria Zilda Cury, de poemas publicados em jornal, sobre Preguiça, diz Drummond que "nem chegou a ser organizado" (p. I62). De qualquer forma, trata-se de um momento da obra poética de Drummond que demanda maior atenção do que tem tido até agora. 
Daisy, como autora e figura histórica, é índice forte das muitas perdas do movimento e também de um processo contínuo de erosão do Modernismo, simultâneo ao seu processo de autodefinição e desenvolvimento de sua autoconsciência.

Pelo olhar retrospectivo, Daisy se apresenta como uma figura cheia de promessas artísticas, muito interessantes na letra e no espírito. No que concerne à escrita dos participantes do grupo, percebe-se sobretudo uma heterogeneidade estilística, que podemos entender como um caráter de transição entre a hipersensitividade melancólica e algo afetada do Simbolismo tardio/Penumbrismo e a exigência de uma vida ativa, saudável, civil e exigente, ou seja, moderna. No caso de Daisy, entretanto, essa transição é acrescida da natureza de sua posição dentro do grupo da garçonnière, o seu agravante de gênero e classe social. Para o melhor entendimento dos escritos de Daisy no diário coletivo, é necessário inseri-la comparativamente no contexto dos diferentes escritos e personagens que habitam $O$ perfeito cozinheiro das almas deste mundo.

Ao nos debruçarmos sobre o diário da garçonnière de Oswald, verificamos a descrição certeira de Mário da Silva Brito quando diz que no caderno "há de tudo: pensamentos, trocadilhos (inúmeros), reflexões, paradoxos, pilhérias com os habitués do retiro, alusões à marcha da guerra, a fatos recentes da cidade, a autores, livros e leituras, às músicas ouvidas" além de uma série de outros elementos, ainda segundo o crítico paulista, como colagens, "um poema pré-concreto de Oswald feito com tipos de carimbo", cartas de amigos, charges da imprensa etc. ${ }^{\text {I3 }}$ Limitadas pelas paredes da garçonnière, as páginas do texto exibem jogos irreverentes com as convenções sociais e de linguagem, bem como com a imagem que se tinha à época de uma literatura séria. Diante da porosidade do diário ao contato da vida íntima e da escrita dos seus autores-personagens, em que o arbitrário se justapõe e produz a imagem de uma composição com lógica própria, Haroldo de Campos o filiou aos experimentos da vanguarda artística e notou a "novidade da estrutura-aleatória e da forma ready-made, de livro-objeto". ${ }^{\text {I4 }}$ Contudo, essa faceta ousada artisticamente aos olhos do poeta concretista convive com outra, a de uma literatura ainda tardo-simbolista/penumbrista, em que os torneios rebuscados da escrita difusos pelo diário traziam, seja por paródia ou mimetismo, a herança ligeiramente modificada do Parnasianismo, que Haroldo denomina de belle époque afraniopeixotesca. Mais importante do que cindir $O$ perfeito cozinheiro... entre uma estética que aponta para o futuro e outra que aponta para o passado, segundo critérios estabelecidos a partir de um marco específico, o da Semana de 22, é perceber em suas páginas a convivência de registros de linguagem diferentes e inquirir se há alguma lógica que os organiza.

O texto inicial do diário, escrito por Pedro Rodrigues de Almeida (João de Barros), mostra-nos um caminho de leitura: ao construir o pórtico do "livro", como o chama o autor, ele mescla um tom solene e paródico que, no entanto, se refere inicialmente a "este seculo de grandes torturados" e prossegue "Si o nosso corpo, depauperado a tóxicos e reduzido às proporções de carcaça degenerada, precisa dos condimentos que reabilitam, não me negará a posteridade deliquescente, que se anuncia, serem almas

I3 BRITO, Mário da Silva. O perfeito cozinheiro das almas deste mundo. In: ANDRADE, Oswald de. O perfeito cozinheiro das almas deste mundo. São Paulo, Globo, I992, p. vii.

I4 CAMPOS, Haroldo de. Réquiem para Miss Cyclone..., op. cit., p. xxii. 
humanas as coisas mais esfomeadas e débeis, que se agitam nesse conflagrado planeta dos absurdos e das inverossimilhanças" (p. I) ${ }^{\text {I5 }}$. Ainda que paródica, a frase longa, a dicção espiritualizante e as almas de corpos intoxicados evocam uma sensibilidade lida nos poemas em prosa de Cruz e Sousa, ou em sua difusão, e com uma "carcaça" que remete, voluntariamente ou não, à poética de Augusto dos Anjos. Entretanto, o texto gradualmente se abre para uma demanda de vida ("as salitradas fatias de bom humor") para ao final dizer "Comendo assim, as almas sans se farão robustas e as doentes susterão, como grande encanto e surpresa, a marcha dos seus males. Será o regimen idéal e hygienico, nada de excessos, nada de indigestões” (p. 2). Agora, a alma a que se refere o texto se trata mais propriamente de um corpo, revigorado pelo perfeito cozinheiro e apto a uma vida ativa e saudável. Leio, no modo como se desenvolvem essas frases afetadas, uma proposta em embrião da passagem de uma sensibilidade crepuscular e deliquescente, torturada e finissecular, para um corpo que se define por um anseio de realidade e de vida, com uma atitude mais moderna diante do mundo. A primeira receita, que se segue ao texto introdutório, expõe o mesmo paradigma: "Nos casos de amor, á Dulcinea prefira-se a Dulce núa” (p. 2). A Dulcineia, com suas implicações quixotescas e idealizantes, é substituída, na vivacidade de um trocadilho, pelo sintagma Dulce nua, em que novamente procura-se substituir a idealidade do espírito pela concretude, agora propriamente erótica, do corpo.

Não será possível, neste ensaio, fazer uma análise detalhada do diário. Quero, entretanto, chamar a atenção para dois elementos nele recorrentes: um comportamento que evoca o boêmio no que tem de provocativo, informal, blagueur e de falta de respeito diante das convenções sociais e de linguagem; e o gosto pelos jogos verbais, especialmente pelo trocadilho. $\mathrm{O}$ que chamo aqui de comportamento boêmio se concretiza em alguns dos momentos mais expressivos do diário, por exemplo, neste trecho de Oswald-Miramar: "Trago rapadura de cidra e uma alma pre-homerica, cheia de pinga com limão Positivamente amanhece na vida” (p. I4), em que a ideia de uma felicidade ingênua adquire uma expressão original, que posteriormente será racionalizada e transformada em plataforma da poesia pau-brasil. Ou neste, de Edmundo Amaral-Viruta: "Reflexão de um dia de aguaceiro: As casas são guarda-chuvas evoluídos, dificilmente portáteis” (p. I85), em que o humor e o jogo verbal se compõem de associações insólitas. O mesmo procedimento está em "O Ferrignac deante da Cyclone é a philarmonica de Rio Claro, em dia de festa" (p. I2), de Miramar. Por fim, estes trechos de Daisy-Cyclone: "Só agora compreendo que o Miramar ama á prestações... com sorteios bi-semanaes” (p. II7). Tais liberdades diante das convenções e da linguagem teciam, involuntariamente, um diálogo com um procedimento contemporâneo da vanguarda francesa, a transformação das posturas boêmias em fórmulas estéticas de provocação e em princípio artístico, presentes, por exemplo, na obra de um Max $\mathrm{Jacob}^{\mathrm{I}}$. Grande parte dessas posturas e

I5 Os números de página se referem a ANDRADE, Oswald de. O perfeito cozinheiro das almas deste mundo (edição fac-similar). São Paulo, Ex-Libris, I987. Todas as demais edições do livro seguem a numeração original do diário.

I6 É possível conectar a linguagem do diário com a sátira jornalística da época, sobretudo com os escritos de Alexandre Marcondes Machado (o Juó Bananere) e de Oswald de Andrade no jornal O Pirralho (I9II-I9I8), 
experimentações, contudo, não ultrapassaram, em seu momento, as paredes da Rua Libero Badaró, n. 67, $3^{\circ}$ andar, sala 2.

De estatuto especial gozam os trocadilhos, frequentes ao longo de todo o diário. Dentre eles, gostaria de destacar os seguintes: "-É preferível ser pente a ser mulher", Miramar (p. II), “A primavera é prima Vera; o verão é o ferrão; o automno é a azeitona”, Oswald-Garoa (p. 56), “Cysne - Cyne - Cysco - Cysclone - Cyclone - Cyclowne”, Léo $\operatorname{Vaz}$ (p. I42) e, por último, o trocadilho mais bem achado do texto: "Rabo de... arraia!/É rabo de saia? Era bode. Saia!”, Oswald-Garoa (p. I43). Se a inspiração para esses jogos de palavras vinha da admiração de Oswald por Emílio de Menezes, o seu funcionamento solto, cifrado e (quase poderíamos dizer) autorreferente o conecta subterraneamente com os "jeux de mots" [jogos de palavras] publicados por Marcel Duchamp e Robert Desnos nos números 5 e 7, respectivamente, da revista Littérature (I9I9-I922, I a Série). No número 7, André Breton teoriza o que ele chama de "mots sans rides" [palavras sem rugas], ao dizer que nos jogos de palavras devem ser observadas: I) a palavra em si mesma; 2) as reações das palavras umas sobre as outras. Por um lado, Breton enfatiza a materialidade das palavras; por outro, observando o estado alucinatório em que Desnos ditou os jeux de mots publicados sob o título "Rose Sélavy", o futuro teórico do Surrealismo percebe nesses escritos um dos fundamentos da escrita automática no modo como as palavras se ordenam por equivalências sonoras e conclui apontando a seriedade desses experimentos: "Jeux de mots quand ce sont nos plus sûres raisons d'être qui sont en jeu. Les mots, du reste, ont fini de jouer. // Les mots font l'amour”ㄱ. O mais notável, e que demanda explicação no caso de $O$ perfeito cozinheiro das almas deste mundo, é a total inconsciência de seus autores-personagens diante da radicalidade e da atualidade dos procedimentos com que compunham os seus escritos.

Diz Haroldo de Campos: “o que nos interessa (e fascina) nesse livro passado é recapturar neles a figuração do futuro"'․ . A relação do diário com o futuro o colocaria na condição de precursor, de uma obra que prediz, entre outras coisas, algo da escrita futura de Oswald, colagens e trocadilhos dada/surrealistas, obras coletivas e anticonvencionais, a mescla arte/vida (em parte wildeana mas com germe de vanguarda), a independência estética e social da mulher moderna etc. Mas nenhum

fundado pelo mesmo Oswald. Contudo, é preciso distinguir entre a ruptura com a literatura tradicional, posta em prática pela vanguarda francesa e posteriormente pelo modernismo brasileiro, e a sátira boêmia do Brasil dos anos I9I0. O espaço desta é pré-determinado e aceito em sua condição circunstancial e efêmera (feita essencialmente para o jornal e a revista, não para o livro). Seu aspecto lúdico e mesmo ferino era socialmente consentido e não abalava a literatura tradicional de então. Ver CHALMERS, Vera. 3 linhas $e$ 4 verdades: o jornalismo literário de Oswald de Andrade. São Paulo, Duas Cidades/ Secretaria de Cultura, Ciência e Tecnologia do Estado de São Paulo, I976. p. 20-2I, 44-53. Especificamente sobre O Pirralho, Chalmers escreve: "A revista é irreverente, mas não ultrapassa o limite do decoro de uma publicação para a gente bem educada” (p. 45).

I7 “Jogos de palavra, quando são as nossas mais seguras razões de ser que estão em jogo. As palavras, de resto, não jogam mais. // Elas fazem amor" [tradução nossa]. BRETON, André. Les mots sans rides. Littérature, Paris, n. 7, p. I2-I4, dec. I922 (Édition Fac-similé, Jean-Michel Place, I978). Exemplo de Desnos: "La solution d'un sage est-elle la pollution d'un page?” (p. I4).

I8 CAMPOS, Haroldo de. Réquiem para Miss Cyclone..., op. cit., p. xxii. 
de seus autores-personagens, porém, dá prosseguimento a esses itens. Oswald dependerá da Semana e do Cubismo literário francês para chegar ao novo estilo, muito mais do que da experiência de $O$ perfeito cozinheiro... ${ }^{\text {9 }}$ Será, então, necessário apreender a contradição real entre potencial, virtualidade e fracasso efetivo. Podemos em princípio notar que essas ousadias, precoces no momento brasileiro em que surgem, são limitadas em dois níveis: I) a convivência com o "estilo de época" pomposo e beletrado, bem como a dicção tardo-simbolista que também caracterizam o livro-diário; 2) a ambientação privada e limitada em que ocorriam os encontros, onde não era possível nem desejável confrontar o espaço público, local em que as convenções agem com força de norma. Essas liberdades estéticas e de comportamento se ressentem da falta de horizonte público e coletivo de seus estilos e posturas. Talvez só Daisy escape um pouco disso, pela confrontação social e de gênero (inclusive com Oswald) geradas por suas posturas, do que falarei em seguida. Tal contradição — eis a minha hipótese - se deve a esse caráter privado, cordial e íntimo, separado da esfera pública - não obstante crítico, sarcástico e criativo —, que "tranca" o diário e impede que ele torne mais agudas ou mesmo solucione as interessantes experimentações nele contidas e que se nos afiguram tão precursoras.

Tereza Virgínia nos alerta para a mediação da forma diário, quando da leitura dos escritos de Daisy, e sobre sua destinação "ao espaço privado, sua inscrição na tradição das escritas íntimas, sobre a não participação da autora no processo de publicação que se dá posteriormente, sobre a não intencionalidade literária dos fragmentos", ${ }^{\circ}$ lembrando que essa escrita, justamente por se restringir à intimidade e não aceder ao espaço público, não se articulava em sistema literário. Se assim retornamos à temporalidade ambivalente do diário, agora podemos colocá-la em outro plano. Ao especificar as suas fronteiras históricas e estéticas, descobre-se nele uma fronteira em que o público e o privado de fato se cruzavam em uma questão de classe e de gênero, pois a participação de Daisy na garçonnière e em O perfeito cozinheiro... acarretava para a normalista, diante das convenções de gênero de então, o olhar reprovador das normas sociais.

Em Memória e sociedade, Ecléa Bosi recolhe depoimento que fala sobre Daisy: "Oswald de Andrade era de gente muito rica. Ele foi a causa de um escândalo na normal no tempo em que fui aluna. Uma moça teve um caso muito comentado com ele: entrava pela porta da Escola e saía pelos fundos para encontrar com Oswald de Andrade". ${ }^{21}$ Para a coesão do diário e da garçonnière, como veremos, essa transgressão de Daisy era fundamental. É Oswald quem diz: "Daisy anima a turma toda"22, opinião que é reiterada pela crítica ${ }^{23}$. Essa função de Daisy se deve fundamentalmente às produções

I9 "Foi durante a longa estada parisiense de I923, a mais demorada de suas permanências fora, que assomou a figura do escritor propriamente moderno que aprendemos a admirar em Oswald”. DANTAS, Vinícius. Oswald de Andrade e a poesia. Novos estudos, São Paulo, n. 30, p. I9I-203, jul.I99I, p. I93.

20 ALMEIDA, Tereza Virgínia de, op. cit., p. II9.

2I Apud FONSECA, Maria Augusta. Oswald de Andrade: biografia. São Paulo, Globo, 2008, p. I05-I06.

22 ANDRADE, Oswald de. Um homem sem profissão..., op. cit., p. I6I.

23 CAMPOS, Haroldo de. Réquiem para Miss Cyclone..., op. cit., p. xxii; ALMEIDA, Tereza Virgínia de, op. cit., p. 42. 
de gênero que ela proporciona, não apenas a sua imagem de "mulher" está em jogo mas igualmente a possibilidade de os outros autores-personagens se construírem como homens. Comparemos a dinâmica de O perfeito cozinheiro... com o poema "Moda dos quatro rapazes”, de Mário de Andrade, publicado em O clã do jabuti (I927):

\section{Moda dos Quatro Rapazes}

\section{Nós somos quatro rapazes}

Dentro duma casa vazia.

Nós somos quatro amigos íntimos

Dentro duma casa vazia.

Nós somos ver quatro irmãos

Morando na casa vazia.

Meu Deus! Si uma saia entrasse

A casa toda se encheria!

Mas era uma vez quatro amigos íntimos... ${ }^{24}$

Mesmo habitada por quatro rapazes, a casa está vazia e monótona. No entanto, o surgimento de uma mulher faria subitamente essa casa ser habitada por cinco pessoas. O que podemos concluir dessa situação descrita por Mário? Que o elemento diferencial trazido pelo gênero feminino não faz somente com que haja uma visibilidade heterossexual homem-mulher, mas que os homens se tornem visíveis entre si pela presença de uma mulher, que passa a ocupar a posição de um prisma por meio do qual todos podem se ver. A presença de Daisy, então, possibilita aos autores-personagens do diário a elaboração entre si, sem constrangimento, de um discurso pautado em seu próprio desejo, gerando um cruzamento de expressões dessa natureza motivadas pela normalista, do qual a própria também participa, fazendo assim da garçonnière e de O perfeito cozinheiro... o que Foucault chama de uma "zona erógena” dentro de um corpo social ${ }^{25}$. Com isso, os desejos dos autores-personagens masculinos transferidos à linguagem não se dirigem somente a Daisy, mas a eles mesmos, criando assim o que Eve Sedgwick Kosofsky chama de "homossocialibidade", conceito contíguo, mas não idêntico, ao de homossexualidade ${ }^{26}$.É a presença/ausência de Daisy que configura a persona artística e de gênero de cada um deles.

Ao longo do diário, todos desejam Daisy (enquanto vivem simultaneamente outros romances), é fato, mas o modo como cada um exibe esse desejo demonstra aos demais participantes um potencial de conquista e virilidade que faz com que seus desejos sejam

24 ANDRADE, Mário. Poesias completas. Rio de Janeiro, Nova Fronteira, 20I3, v. I, p. 235.

25 FOUCAULT, Michel. Histoire de la sexualité I: la volonté de savoir. Paris, Gallimard, I994, p. I99.

26 SEDGWICK, Eve Kosofsky. Between men: English Literature and Male Homosocial Desire. New York, Columbia University Press, I985. 
acrescidos e intensificados por um olhar competitivo. Com essa marcação da diferença de gênero e sua funcionalidade na organização da composição do diário, é necessário, entretanto, notar que Daisy usufrui nele de um estatuto dúplice de igualdade e desigualdade: igualdade no espaço da escrita, desigualdade na construção de gênero. Antes de acompanhar o processo por meio do qual Daisy manteve seu estatuto de igualdade, convém notar como os demais autores-personagens do diário construíram a desigualdade e de que modo isso se reproduziu na crítica. Ao compartilhar com seus companheiros suas conquistas amorosas, reafirmando seu estatuto de igualdade, Daisy escreve que arrumou um namorado japonês, "que possue o lindo nome e Harussam" (p. 68), e recebe como resposta um dos solenes trechos de Pedro Rodrigues de Almeida (João de Barros), no qual, antes de oferecer uma estranha justificativa ("Tudo que você faz é legítimo, porque você é mulher, e inteira, completa, totalmente mulher"), ele pede para que Daisy nunca lhe mostre no futuro "os rebentos amarellos e oleosos d'esse amor desastrado" (p. 68) ${ }^{27} \mathrm{O}$ fragmento é uma pérola em todos os sentidos porque, além do preconceito racial medonho, ele já lança mão de uma punição preventiva contra o novo amor de Daisy: dele decorrerão filhos “feios" como um fardo de seus descaminhos de mulher... Ou seja, ele interpõe a desigualdade como desforra.

De modo geral, três são as formas de marcar a desigualdade de Daisy segundo a construção de gênero. A primeira, reverberada pela crítica, é a de que ela é "fugidia" e "misteriosa", a "sphinge do deserto do Braz", no dizer de Edmundo Amaral-Viruta. Embora, do meu ponto de vista, os autores-personagens construam Daisy como fugidia porque eles não a podem possuir, essa imagem foi recuperada pela crítica como um tipo de "essência feminina", fatal e romântica, da normalista. Mas será Daisy mais “fugidia" do que Oswald ou qualquer homem jovem, irreverente e ousado da época? A segunda forma é a subordinação de Daisy a um momento da biografia de Oswald de Andrade, em que ela seria somente uma etapa da construção de sua obra ou de sua personalidade literária. Mário da Silva Brito dirá que, depois do enterro de Daisy, "estava encerrada uma etapa da vida de Oswald”. ${ }^{8}$ Haroldo de Campos é ainda mais taxativo:

Deise é a pré-Pagu da Idade Boêmia de Oswald de Andrade. [...] Musa crepuscular e agônica, sua morte prematura, dolorosa, joga o irresponsável e destroçado Miramar num outro tempo de sua carreira de escritor e de homem: ele começa a experimentar forças e amadurecê-las para as escaramuças do Modernismo, a afiar sua navalha crítica para os anos polêmicos dos romances-invenções da década de 20 que se anuncia. ${ }^{29}$

Seria difícil construir um raciocínio mais teleológico e enviesado. Por último, Daisy é diferenciada pelo gênero ao ser encerrada em um viés teórico que a instrumentaliza de maneira excessiva. Haroldo é pioneiro nesse sentido, ao enfeixá-la em um paradigma literário, “o modelo romanesco das 'almas de ficção”’30,

27 O mesmo Pedro buscava cortejá-la à p. 9 ao descrevê-la como mulher moderna.

28 BRITO, Mário da Silva. O perfeito cozinheiro..., .op. cit., p. x.

29 CAMPOS, Haroldo de. Réquiem para Miss Cyclone..., op. cit., p. xv.

30 Idem, ibidem. 
em que, posta na linhagem de Lucíola e Iracema, ela "morre por amor” ${ }^{31}$. Só que Daisy não morre "por amor", mas pelas consequências de um aborto, por sua vez derivado dos ciúmes de Oswald, do "cada vez mais enamorado e possessivo Miramar"32. Seria mais produtivo criticamente transferir esse passo biográfico do plano do "paradigma literário" para o das relações sociais e de gênero.

Uma visão geral dos escritos de Daisy em O perfeito cozinheiro das almas deste mundo dá a impressão de uma obra em potencial, de caráter original mas incompleto, amorfo ou sem a forma mais adequada que seu material pediria, o que lhe confere um estatuto inicial de matéria-prima. Entretanto, não convém aceitar que os escritos de Daisy sejam só um espaço incompleto, vazio, a ser ocupado pela Teoria para os seus próprios propósitos. Melhor será dar concretude à sua vida e à sua escrita mesmo sabendo que uma de suas principais características é a sua incompletude, a qual, porém, deve ser entendida em si mesma e não como um espaço vago para a “ausência lilás” ou para a teleologia (pré-Pagu). Se pensarmos de modo comparativo, no momento em que o diário é escrito, a ideia de uma obra apenas em potencial é compartilhada por diversos de seus autores-personagens, inclusive Oswald, à época autor somente de peças de teatro em francês, escritas com Guilherme de Almeida, e de escritos para jornal, em que se destacam os publicados em O Pirralho (I9II-I9I8)33. Assim, se Oswald parasse de escrever em I9I9, os seus escritos do diário dariam a mesma impressão de promessa não realizada, de potencial criativo perdido que temos diante dos escritos de Daisy no trabalho coletivo. Portanto, abordando sincronicamente a sua "obra”, ele se encontra basicamente na mesma condição de seus companheiros de garçonnière.

Daisy, inicialmente, é o contraponto espirituoso de Oswald, dando continuidade, nas primeiras páginas do diário, ao diálogo relatado em Um homem sem profissão sobre os homens e as mulheres, citado no começo deste artigo. Ao longo de $O$ perfeito cozinheiro..., porém, a autora-personagem desenha um perfil próprio, uma forma singular de compor a sua escrita conforme os valores estéticos de transição já esboçados no discurso inicial de Pedro Rodrigues (João de Barros). Daisy transita entre os polos do mais carregado decadentismo à mais ágil escrita que hoje entendemos como moderna. Oswald, em suas memórias, notará somente o primeiro polo: "nas suas notas do diário da garçonnière como em suas cartas, resultava muitas vezes um

\footnotetext{
3I Idem, ibidem.
}

32 Idem, ibidem.

33 Aqui é preciso ter cautela para não difundir a imagem retrospectiva de um Oswald exclusiva e essencialmente rebelde em cada uma de suas "metamorfoses" sem verificar, para todas elas, a sua contradição correspondente. Um desses equívocos, por exemplo, é confundir os capítulos de Memórias sentimentais de João Miramar publicados em I9I6 e I9I7 (em O Pirralho ou A Cigarra) com os do livro de I923-I924. O que há entre as duas versões não se restringe a um processo de correção ou aprimoramento, mas uma verdadeira ruptura. Ao colocar em contraste as duas versões, Haroldo de Campos observa, entre elas, "um laborioso e lúcido percurso estilístico, da banalidade e do convencionalismo de um relato de viagem ao gosto duvidosamente crepuscular das elites da época até a violência criativa da prosa cubista”. CAMPOS, Haroldo de. Metalinguagem e outras metas. São Paulo, Perspectiva, 2004, p. I03. Embora Haroldo enfatize a continuidade, creio ser possível notar a diferença evidente entre as duas estéticas. 
sentimento iniludível de doença, de morte e de frustração"34. Esse sentimento é visível em trechos como este: "Que será que eu tenho em mim? Uma ansiedade má que me tortura um pouco... Sinto a premeditação que a alma tem para a desgraça! Que será que eu tenho em mim?... A medalha mostrou-me o reverso...” (p. I38). Os momentos em que se utiliza do estilo tardo-simbolista/decadentista recuperam seus momentos de saúde debilitada, de pressões familiares e distanciamento forçado dos companheiros. Uma das demonstrações mais tácitas do estatuto de igualdade que Daisy goza no espaço da escrita é a reprovação que ela sofre quando sobrecarrega esse padrão. Há um trecho em que, entre outras coisas, escreve "Soffro com intermitências causticas com um sentir doentio de mulher sensivel e nervosa” (p. I48), ao que Ignácio Ferreira da Costa (Ventania) responde: "Dôr de barriga littteraria? Caramba, Cyclone!” (p. I48). Ao comentar as cartas excessivamente sentimentais enviadas do seu distanciamento forçado na cidade de Cravinhos, um trecho sem autoria registra: "Dasÿ continua a fazer literatura cravinhense” (p. I93), referindo-se certamente à aliança entre convencionalismo excessivo e provincianismo.

Se, de fato, tanto nas memórias de Oswald como no diário, Daisy está constantemente mal de saúde, sua escrita, além das características descritas por Oswald, possui igualmente desenvoltura e uma sadia ironia, capaz de levar a cabo um jogo constante de esquivanças com os demais autores-personagens. Com frequência, ela responde às investidas que recebe sem confrontação, mas desarmando humoristicamente o argumento. Pedro Rodrigues (João de Barros) sugere a existência de um triângulo entre ele, Daisy e Oswald, pedindo "Acima de tudo, sejamos leaes, prudentes e sensíveis”, e Oswald-Miramar interpela a moça: “Daisy, você fica insensível deante d'isso?", ao que ela responde: "Fico imprudente e desleal” (p. 2I), numa frase em que, se esquivando das intimidações, mantém sua independência sem rechaçar os seus pretendentes. Às investidas de ciúmes de Oswald por conta de uma conquista de Daisy no bairro do Brás, ela responde: "Miramar, o agente secreto da minha encrenca mysteriosa... O Thyrso Martins da minha policia Braz....ileira” (p. 88), em que a caracterização do desenvolto e amasiado Oswald como policial de subúrbio certamente continha, ou ao menos denunciava explicitamente, a ausência de direitos dele sobre ela. Mais importante, contudo, do que esses jogos amorosos é o fato de Daisy incorporar em sua escrita a mesma liberdade usada por seus companheiros, mostrando que ela sabia absorver, atualizar e produzir os discursos e registros linguísticos do grupo boêmio para os seus propósitos.

A escrita propriamente ousada e provocativa pode ser verificada em uma

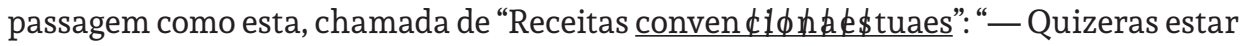
no convento?/ Nú com vento?/ ...!!!/ Preferia estar nua com garôa” (p. I05). O trecho joga com polaridades típicas das atribuições do gênero feminino: ou a castidade do convento, ou a total disponibilidade sexual (a nudez). Não obstante, Daisy inclui nesse jogo a posição criteriosa pela qual dispõe sua nudez, que se deve menos às condições climáticas do que aos apelidos dos companheiros: Ventania = Inácio Ferreira da Costa, Garoa = Oswald. A autora funde na escrita ágil o trocadilho, o humor e a noção de independência a partir das convenções do feminino, demonstrando sua

34 ANDRADE, Oswald de. Um homem sem profissão, op. cit., p. I85-I86. 
capacidade literária, análoga (ou seja, nem superior, nem inferior) aos melhores momentos de Oswald. Por último, vale a pena ler uma passagem de Daisy que, em um registro mais livre, descreve um passeio com Oswald:

9 horas... partimos os dois pela manhã, franjada ainda de nevoeiros húmidos. E o ceu tão alto... e tão azul! A paysagem que nos corria a beira do auto, tinha espanejamentos bruscos de vida e a cidade ao longe, batida de somnolencia era como esses desenhos a cores, que um papel de seda encobre por inteiro. E a capelinha clara que assombrava com seu traço o scenario de luz, se desfazendo da nevoa, surgiu radiosa e linda, a nos ditar na majestade real todo um poema de uncção e de verdade (p. Io8).

Embora o tom da escrita se aproxime do poético, seria temerário encerrá-lo em uma definição de gênero literário. Prefiro dizer que se trata não de poesia, mas de matéria-prima de poesia, de uma condensação subjetiva e de linguagem, próxima ao poético35. Nele, é possível notar os véus e as névoas do simbolismo tardio se desfazendo diante de um paisagismo que se elabora a partir de um carro, e de que surge, radiosa e linda, uma simples capelinha clara. Mesmo com a grandiloquência final do "poema de unção e verdade", o que se vê é a abertura de Daisy para a linguagem ainda heterogênea das melhores passagens do diário como um todo, em que as neblinas penumbristas convivem com uma solaridade moderna em estágio inicial, que nela se casa a uma sensibilidade mais carregada de doenças físicas e pressões sociais, embora equilibrada pelas demandas enfáticas de independência, liberdade e criatividade.

Assim, ao olhar para o conjunto dos escritos intermitentes de Daisy-Cyclone ao longo de $O$ perfeito cozinheiro das almas deste mundo, percebemos que a forma indefinida, híbrida de literatura, carta, diário e conversa, faz o amálgama do momento em que escreve. É a forma livre, permitida pelo diário, que reflete uma subjetividade cujo potencial acabou por não se definir em um contexto social que visa impedir a constituição de uma subjetividade feminina e moderna de fato. Contudo, é preciso concluir que a multiplicidade de registros visaria ao uno, a uma plenitude que não surge, e não a uma abstrata pluralidade pós-moderna. Ainda assim, mesmo no pouco que sobrou de seus escritos, é possível ver que Daisy se consolidou como uma personalidade: ela adquiriu o direito de ser idêntica a si mesma, por isso não é possível chamá-la de "pré" ou "pós" alguma coisa, como "pré-Pagu" ou "pós-Lucíola" ${ }^{6}$. Uma leitura atenta, então, faz com que os escritos e a personalidade de Daisy adquiram um dinamismo próprio, capaz de fazer todo esse contexto gravitar em torno de si.

35 Oswald dirá a propósito desse trecho: "Levo Daisy a uma miraculosa capelinha qualquer. Ela literateja. Fomos de automóvel” (ANDRADE, Oswald de. Um homem sem profissão, op. cit., p. I72). Contudo, essa "capelinha qualquer" evoca diretamente o seu poema "Ditirambo": "Meu amor me ensinou a ser simples/ Como um largo de igreja/Onde não há nem um sino/Nem um lápis/Nem uma sensualidade”, embora seja necessária certa cautela para afirmar que houve aí recuperação da escrita de Daisy.

36 É compreensível que ela compartilhe uma série de condições histórico-sociais com Pagu, o que não é necessário desconhecer, mas que não devem ser colocadas numa relação de hierarquia ou subordinação. Seria possível, por exemplo, chamar Oswald de "pós-Emílio de Menezes” ou de "pré-Haroldo de Campos"? 
Para a comprovação dessa perspectiva, e à guisa de conclusão, esboçarei aqui uma interpretação de Oswald a partir de Daisy, uma tentativa de entrar na obra de Oswald via Daisy. Oswald ocupa uma posição especial quanto ao fenômeno Daisy, pois ele é, ao mesmo tempo, a sua condição de possibilidade e o fator de sua obliteração. Por isso, o estudo de Daisy se desdobra naturalmente em um estudo sobre Oswald, o qual permite simultaneamente que ela surja, possua existência literária e, de certo modo, ocupe a posição de sujeito, mas igualmente dá o desfecho fatal de sua vida, por uma crise de ciúmes. Maria Augusta Fonseca nota que, diante das tentativas de emancipação feminina: "Oswald de Andrade tem um importante papel nessa empreitada. Escandalizando sua própria classe social, quase sempre se uniu a mulheres que desafiaram normas de comportamento de seu tempo"37.Porém, ele ainda transigia entre a tendência libertária e a reiteração da norma sexista e "nem sempre dominou impulsos na direção contrária" ${ }^{8}$. No caso de Daisy, a sua crise de ciúmes pela desconfiança em relação à paternidade do filho que ela carregava reativava o que se pode chamar de uma "performance de gênero" patriarcal ${ }^{39}$. É nesse momento extremo que as condições de gênero se manifestam de maneira mais enfática e trágica. Aqui, de modo sinistro, pode ser recontextualizada a frase de Foucault de que "la sexualité devient le chiffre de l'individualité" 40 . Se, ao longo do diário da garçonnière, Oswald se vinculava preponderantemente a uma ideia de sexualidade livre, atuando performances de gênero em que a noção de fidelidade e propriedade ficavam abaladas, no caso da gravidez de Daisy, por tê-la visto entrar em uma "pensão de rapazes", ele ativa uma atitude possessiva que leva ao desfecho trágico.

A morte de Daisy e o encerramento precoce de sua potencialidade literária se devem, então, primeiro a uma questão de gênero, à “fatalidade”, já anunciada naquela horrenda passagem Pedro Rodrigues (João de Barros) sobre os futuros "filhos amarelos" de Daisy, ou seja, a transgressão da norma sexual seria punida com uma gravidez indesejada ou, nesse caso, segundo a perspectiva de Oswald, infiel. Em segundo lugar, de maneira mais mediada, ela se deve a uma questão de classe, pois as promessas de uma sexualidade libertada, plataforma implícita no modo como Oswald conduzia sua garçonnière, foram levados a sério por Daisy que, no entanto, proveniente de família modesta, não teria como arcar com uma vida independente sem o apoio de Oswald. O herdeiro do Sr. Andrade, que acenou para a normalista

37 FONSECA, Maria Augusta, op. cit., p. 95-96.

38 Idem, p. 96.

39 Sigo, em relação à questão de gênero, BUTLER, Judith. Gender trouble: feminism and the subversion of identity. New York, Routledge, 2008. A importância da teoria de Judith Butler, em que o gênero se define por uma série de atos repetidos segundo convenções pré-determindas — as "perfomances" de gênero — reside, nesse caso, na ruptura com noções essenciais e/ou unívocas de gênero. Assim, Oswald não é exclusivamente libertário ou patriarcal em relação às mulheres, mas alterna performances nas duas frentes. Igualmente, Daisy não é essencialmente mulher, mas incorpora e se afasta alternadamente das convenções do gênero feminino de acordo com as estratégias da sua escrita. Nesse sentido, a "falha" de Daisy, aos olhos de Oswald, foi conduzir sua vida sexual segundo as "performances" atribuídas ao gênero masculino, daí a sua desconfiança passional e possessiva.

40 FOUCAULT, Michel, op. cit., p. I92. 
Maria Lourdes Pontes com o horizonte de superação de uma vida provinciana e limitada, "contra fascinações roceiras", como ela diz em uma das cartas anexadas ao diário (p. I87), foi o mesmo que reativou a estrutura mental do patriarca em sua demanda de posse diante de "esposa e filho".

Em que isso contribui para um novo entendimento da personalidade de Oswald e de sua obra literária? Uma das conclusões que o livro/diário permite tirar é sobre a figura de Oswald: a um tempo libertária e anuladora. Assim, vemos toda a liberdade possível de um homem detentor do privilégio, que esgarça a sua liberdade de privilegiado ao paradoxo do libertário, social, artístico e sexual, e cuja consequência pode ser minar as bases do próprio privilégio. No entanto, sem aviso prévio, ele pode ativar a dimensão sinistra do patriarca: arbitrário, inconstante, intransitivo, destrutivo e sem alteridade. Em outras palavras, uma presença autoritária que exige a eliminação da diferença, da liberdade alheia. Esse paradoxo o acompanhará por toda a sua vida. Oswald nunca fez os pressupostos histórico-sociais (de classe) de sua própria existência social e artística passarem por um rigoroso processo de autocrítica, embora nunca tenha se confinado nos limites preestabelecidos pelas normas de sua classe. Com isso, o percurso de sua obra não se apresenta como cumulativo, mas proteico. As experiências de uma etapa não conformam qualitativamente a etapa seguinte.

Não se trata de dizer que não haja crítica na obra e na personalidade de Oswald, mas o que é crítico nele é mais a extrapolação de uma posição/condição de classe e menos o antagonismo consciente em relação a ela, o qual também existe, por exemplo, no "Prefácio" a Serafim Ponte Grande (I933) ou em O rei da vela (I937). No entanto, essa extrapolação de classe possui um efeito simultaneamente libertário e destrutivo, original em seu comportamento social, em sua escrita polêmica e em sua obra literária, mas que também arrastava potencialmente para a destruição a vida daqueles mais fracos do que ele, como Daisy, ou abandonava incompleta e/ou em fragmentos etapas inicialmente ambiciosas de seu trabalho literário, como a Antropofagia. Em seu momento positivo, Oswald supunha que os seus privilégios, como os prazeres do corpo e do intelecto, dos quais ele só usufruía por causa da sua posição de classe, deveriam ser algo acessível a todos, como uma espécie de direito natural do homem libertado, o que ele, de modo original e canhestro tentou formular nos seus dois últimos livros teóricos, A crise da filosofia messiânica (I950) e A marcha das utopias (I966, publicação póstuma)4َ. Em seu momento deletério, Oswald não percebia que seu privilégio não era generalizável, que, por exemplo, sua exigência de liberdade sexual mudava de contexto e era virtual e praticamente destrutiva no caso de Daisy e, em certa medida, de Pagu.

Embora a relação entre obra e vida deva ser necessariamente mediada pela forma artística, é possível perceber aqui um ponto de convergência entre as contradições da atuação social de Oswald e a lógica de seu desenvolvimento artístico. Em ambas, as oscilações de uma atitude polemista impunham saltos constantes e mudanças, em atropelo e sem aviso prévio, de paixões, plataformas estéticas, posições políticas e elaborações formais, cuja única coerência se fundava na personalidade de seu criador.

4I Nos quais, sintomaticamente, a defesa do matriarcado era baseada na defesa do filho de direito materno, o que implicava a ausência de direitos do pai sobre o filho. 
Sendo a personalidade de Oswald, dessa forma, elemento fundante e aglutinador de uma série de manifestações, muitas vezes incoerentes, biográficas e literárias, é nela que a reflexão encontra a solidez necessária para formular um julgamento interpretativo englobante. Desse modo, lidos a contrapelo, seu comportamento ferino, volúvel na troca constante dos insultados, e suas mudanças estéticas, não acompanhadas das devidas explicações, conformam a postura de quem acha que não deve prestar contas a ninguém, um tipo de impunidade que pressupõe uma posição de classe. Assim, a personalidade e a obra de Oswald podem ser consideradas uma mistura confusa e vertiginosa de elementos avançados e retrógrados, progressistas e reacionários, derivada dessa extrapolação de classe.

Nessa tentativa de interpretar a lógica da personalidade de Oswald a partir da experiência histórico-social e estética de Daisy, podemos concluir que as ousadias de Oswald, tanto na vida como na literatura, baseavam-se mais em um radicalismo de impulso do que em uma profunda densidade reflexiva ${ }^{42}$. Nesse caso, observa-se a reciprocidade nele de transgressão provocadora e transigência de classe, o que configura a produtividade ambivalente de uma posição de poder. Se a continuidade da obra e da atuação de Oswald — as suas "metamorfoses", como chamou Mário da Silva Brito -construíam uma imagem do Modernismo brasileiro, ela igualmente acumulava ruínas e fragmentos das etapas não recuperadas, criando um movimento que se erodia na medida em que avançava. Recuperar os escritos e a personalidade de Daisy cria, desse modo, a possibilidade de abordar e conhecer Oswald por outro ângulo, reconhecer a lógica e algumas linhas de força do Modernismo brasileiro, bem como suas perdas, o que contribui decisivamente para uma revisão desse movimento.

\section{SOBRE O AUTOR}

LEANDRO PASINI é professor de Literatura Brasileira na Universidade Federal de São Paulo (UNIFESP). Possui mestrado e doutorado em Teoria Literária e Literatura Comparada pela Universidade de São Paulo (USP). É autor de $A$ apreensão do desconcerto: subjetividade e nação na poesia de Mário de Andrade (São Paulo: Nankin, 2013). E-mail: leandro.pasini@unifesp.br

REFERÊNCIAS BIBLIOGRÁFICAS

42 Note-se, por exemplo, como a escrita do poderoso “Prefácio" a Serafim Ponte Grande é mais eletrizada por um impulso (auto)crítico do que medida e esfriada na densidade da reflexão e da análise (auto)crítica. 
ALMEIDA, Tereza Virgínia de. A ausência lilás da Semana de Arte Moderna: o olhar pós-moderno. Florianópolis, Letras Contemporâneas, I998.

ANDRADE, Carlos Drummond de. Os 25 poemas da triste alegria. São Paulo, Cosac Naify, 2012.

ANDRADE, Mário. Poesias completas. Rio de Janeiro, Nova Fronteira, 20I3, v. I.

ANDRADE, Oswald de. O perfeito cozinheiro das almas deste mundo (edição fac-similar). São Paulo, Ex-Libris, I987.

.Um homem sem profissão I: sob as ordens de mamãe. São Paulo, Globo, 2002.

BOAVENTURA, Maria Eugênia. O salão e a selva: uma biografia ilustrada de Oswald de Andrade. Campinas-SP/ São Paulo, Edunicamp/ Editora Ex Libris, I995.

BRETON, André. Les mots sans rides. Littérature, Paris, n. 7, p. I2-I4, dec. I922 (Édition Fac-similé, Jean-Michel Place, I978).

BRITO, Mário da Silva. A Revolução Modernista. In: COUTINHO, Afrânio (org.). A literatura no Brasil. São Paulo, Global, 2004, v. 6.

. As Metamorfoses de Oswald de Andrade. In: Ângulo e horizonte. São Paulo, Livraria Martins, I969, p. 5-Io.

. História do modernismo brasileiro. Rio de Janeiro, Civilização Brasileira, I997 (I ${ }^{\mathrm{a}}$. Ediçãa de I958).

O perfeito cozinheiro das almas deste mundo. In: ANDRADE, Oswald de. O perfeito cozinheiro das almas deste mundo. São Paulo, Globo, I992, p. vii.

BUTLER, Judith. Gender trouble: feminism and the subversion of identity. New York, Routledge, 2008.

CAMPOS, Haroldo de. Metalinguagem e outras metas. São Paulo, Perspectiva, 2004. . Réquiem para Miss Cyclone, musa dialógica da pré-história textual oswaldiana. In: ANDRADE, Oswald de. O perfeito cozinheiro das almas deste mundo. São Paulo, Globo, I992.

CANDIDO, Antonio. A Revolução de 30 e a Cultura. In: A educação pela noite. Rio de Janeiro, Ouro sobre Azul, 2006. . Literatura e Cultura e I900 a I945.In: . Literatura e sociedade. Rio de Janeiro, Ouro sobre Azul, 2008.

CHALMERS, Vera. 3 linhas e 4 verdades: o jornalismo literário de Oswald de Andrade. São Paulo, Duas Cidades/ Secretaria de Cultura, Ciência e Tecnologia do Estado de São Paulo, I976.

CURY, Maria Zilda Ferreira. Horizontes modernistas: o jovem Drummond e seu grupo em papel jornal. Belo Horizonte, Autêntica, I998.

DANTAS, Vinícius. Oswald de Andrade e a poesia. Novos estudos, São Paulo, n. 30, p. I9I-203, jul.I99I. FONSECA, Maria Augusta. Oswald de Andrade: biografia. São Paulo, Globo, 2008.

FOUCAULT, Michel. Histoire de la sexualité I: la volonté de savoir. Paris, Gallimard, I994.

LARA, Cecília de. Introdução. In: . Pressão afetiva e aquecimento intelectual: cartas de Antônio de Alcântara Machado a Prudente de Moraes, neto. São Paulo, Giordano/ Lemos/ Educ, I997.

SEDGWICK, Eve Kosofsky. Between men: English Literature and Male Homosocial Desire. New York, Columbia University Press, I985. 